\title{
ANÁLISE ESTATÍSTICA E CURVA DE SUPERFÍCIE DOS RENDIMENTOS DA EXTRAÇÃO POR SOLVENTE DO ÓLEO DE PINHÃO MANSO
}

\author{
B. K. S. A. ANDRADE ${ }^{1}$, J. I. SOLETTI ${ }^{1}$, S. H. V. de CARVALHO ${ }^{1}$ \\ ${ }^{1}$ Universidade Federal de Alagoas, Departamento de Engenharia Química \\ E-mail para contato: bazkarolinne@gmail.com
}

\begin{abstract}
RESUMO - O pinhão manso é uma fonte rica em óleo e de fácil cultivo. Desta forma, este trabalho tem como objetivo estudar o processo de extração por solvente do óleo de pinhão manso. No processo de extração por solvente foram avaliados os métodos (Soxhlet e contínuo), as granulometrias (Tyler \# 14/20 e \# 28), os solventes (etanol e metanol) nos tempos de 1 e 3 horas. Através de análises estatísticas foi observado a influência dessas variáveis no rendimento do processo. O solvente, o tempo e a interação solvente/método se apresentaram como uma variáveis determinantes sobre o rendimento. Através desses resultados foi possível desenvolver um modelo do processo de extração por solvente em função das variáveis significantes.
\end{abstract}

Palavras-chaves: Pinhão manso, extração por solvente, óleo.

\section{INTRODUÇÃO}

O pinhão manso (Jatropha curcas L.) é cultivado no continente americano desde a época pré-colombiana, porém ainda não é uma espécie totalmente domesticada. Tem sido estudado como potencial matéria-prima na produção de biodiesel devido ao elevado teor de óleo. Além de ser adaptável a condições climáticas variáveis, resistir a longas estiagens, ser rústico e perene, seu ciclo produtivo é de aproximadamente 40 anos (PEREIRA, 2009).

\subsection{Extração por solvente}

A extração por solvente é uma opção mais eficiente. Independentemente do teor de óleo inicial do material a extrair, o emprego do solvente tem a vantagem de garantir um completo desengorduramento do grão, produzindo um resíduo com menos de 1\% de óleo (OETTERER, REGITANO-D'ARCE, SPOTO, 2006; MORETTO \& FETT, 1986 citado por CORREIA, 2009)

Consiste em dois processos: um deles rápido e fácil, o de "dissolução", e o outro mais demorado dependente de "difusão" da mistura de óleo e solventes através da parede celular semipermeável. Assim, durante a extração, a velocidade do desengorduramento da semente é no começo muito rápido, decrescendo com o decurso do processo (CORREIA, 2009). Os componentes contidos em uma matriz sólida são extraídos dissolvendo-os em um solvente líquido. A solução obtida chamada de miscela (óleo + solvente) é removida do extrator e encaminhada para um evaporador para a remoção do solvente (PEREIRA, 2009). 
A extração pode ser realizada pelo método de Soxhlet e pelo contínuo. O primeiro é um processo com bateladas contínuas, onde há acúmulo de solvente junto à amostra. E o segundo como o próprio nome diz é um processo contínuo, sem acúmulo de solvente.

Este trabalho tem como objetivo analisar a eficiência dos processos de extração por solvente, avaliando as variáveis interferentes como: solvente, tempo, método e granulometria.

\section{METODOLOGIA}

Para a extração por solvente, as sementes de pinhão manso foram trituradas e peneiradas em peneiras da série Tyler (W.S. Tyler, USA) de acordo com duas granulometrias: Tyler \#14/20 (1,19/0,84 mm) e \#28 (0,59 mm).

A extração por solvente foi realizada em duplicata pelos métodos Soxhlet padrão e contínuo, com etanol e metanol, granulometrias de Tyler \#14/20 e \#28 e nos tempos de 1 e $3 \mathrm{~h}$ no equipamento B-811 da BUCHI. Os experimentos avaliaram os tipos de métodos, o solvente, a granulometria e o tempo.

Cerca de $10 \mathrm{~g}$ de pinhão manso triturado na granulometria determinada foi envolvido em papel filtro e introduzido no extrator. $\mathrm{O}$ béquer do equipamento foi preenchido com 250 $\mathrm{mL}$ do solvente determinado. O B-811 foi programado de acordo com o tempo e o método.

As extrações foram feitas segundo o planejamento para o fatorial $2^{4}$ mostrado na Tabela 1 em duplicata. Na qual $\mathrm{x}_{1}$ é a granulometria, $\mathrm{x}_{2}$ é o solvente, $\mathrm{x}_{3}$ é o método e $\mathrm{x}_{4}$, o tempo. Em relação à granulometria o fator (-1) representa Tyler \#14/20 e o (1), Tyler \#28; ao solvente, (1) é o metanol e (1), etanol; ao método, (-1) é o contínuo e (1), Soxhlet; e ao tempo, (-1) é $1 \mathrm{~h}$ e (1), $3 \mathrm{~h}$.

Tabela 1 - Matriz do planejamento $2^{4}$

\begin{tabular}{ccccc}
\hline Ensaio & $\mathrm{X}_{1}$ & $\mathrm{X}_{2}$ & $\mathrm{X}_{3}$ & $\mathrm{X}_{4}$ \\
\hline 1 & -1 & -1 & -1 & -1 \\
2 & 1 & -1 & -1 & -1 \\
3 & -1 & 1 & -1 & -1 \\
4 & 1 & 1 & -1 & -1 \\
5 & -1 & -1 & 1 & -1 \\
6 & 1 & -1 & 1 & -1 \\
7 & -1 & 1 & 1 & -1 \\
8 & 1 & 1 & 1 & -1 \\
9 & -1 & -1 & -1 & 1 \\
10 & 1 & -1 & -1 & 1 \\
11 & -1 & 1 & -1 & 1 \\
12 & 1 & 1 & -1 & 1 \\
13 & -1 & -1 & 1 & 1 \\
14 & 1 & -1 & 1 & 1 \\
15 & -1 & 1 & 1 & 1 \\
16 & 1 & 1 & 1 & 1 \\
\hline
\end{tabular}


As misturas óleo-solvente foram conduzidas para o processo de separação no próprio extrator. O rendimento de óleo foi estimado através da diferença entre a massa da amostra inicial e a massa de amostra final.

\section{RESULTADOS}

$\mathrm{Na}$ extração por solvente foi avaliado o solvente, o tempo, o método e a granulometria. A Tabela 2 apresenta os rendimentos obtidos utilizando o etanol como solvente com tempos de extração de 1 e 3h, nos métodos Soxhlet e contínuo em granulometrias de Tyler \#14/20 e $\# 28$.

Tabela 2 - Rendimentos da extração por etanol e metanol

\begin{tabular}{ccccc}
\hline \multirow{2}{*}{ Método } & Tempo (h) & $\begin{array}{c}\text { Granulometria } \\
\text { (Tyler \#) }\end{array}$ & \multicolumn{2}{c}{ Rendimento (\%) } \\
& \multirow{2}{*}{ Soxhlet } & $14 / 20$ & 71,46 & Metanol \\
\cline { 2 - 5 } & \multirow{2}{*}{3} & 28 & 78,99 & 41,66 \\
& $14 / 20$ & 100 & 64,91 \\
& \multirow{2}{*}{ Contínuo } & 28 & 100 & 81 \\
\cline { 2 - 5 } & \multirow{2}{*}{3} & $14 / 20$ & 64,75 & 23,12 \\
& & 28 & 74,88 & 33,65 \\
\hline
\end{tabular}

O tempo de imersão da amostra no solvente pelos constantes ciclos que renovavam o solvente possibilitou maiores rendimentos obtidos através do método de Soxhlet. O tempo de 1 hora é insuficiente para atingir o máximo de rendimento da extração. As duas horas a mais proporcionaram um rendimento $30 \%$ mais elevado, aproximadamente. Deve-se então analisar a viabilidade do custo do processo em função do rendimento.

O rendimento apresentou uma pequena elevação para uma menor granulometria. Isso pode ser explicado pelo fato do solvente percolar os interstícios da semente mais triturada com maior facilidade.

Realizando uma análise comparativa entre os solventes nota-se uma superioridade do rendimento obtido com a utilização do etanol. Com o metanol, em nenhum dos métodos foi possível obter $100 \%$ de extração. Nota-se que o etanol é melhor que o metanol, possivelmente devido à maior polaridade das moléculas envolvidas na extração. Lipídeos costumam ser fracamente polares, como o etanol é menos polar que o metanol é mais solúvel nos óleos, isto garante maiores rendimentos de extração.

\subsection{Análise estatística dos resultados}


$\mathrm{O}$ planejamento experimental do projeto foi feito pelo método fatorial $2^{\mathrm{k}}$ que consiste em realizar testes com cada uma das combinações da matriz experimental (GALDÁMEZ, 2002). A análises estatísticas foram realizadas com o auxílio do software STATISTICA 9.

Foram obtidos através do STATISTICA os efeitos principais e os efeitos de interações sobre o rendimento. O primeiro é a mudança da resposta média ao alterar um fator de $(-1)$ para (1) com os demais constantes. $\mathrm{O}$ segundo, mudança do resultado com a interação de dois ou mais fatores.

Apenas três valores absolutos foram significativos para um intervalo de confiança de 95\% (apresentam $\mathrm{p} \leq 0,05$ ). O solvente e o tempo que foram as variáveis que mais contribuíram para aumento do rendimento da extração, muito significativas, e interação solvente/método que reduziu o rendimento é significativa. A influência de cada fator sobre o rendimento pode ser observada na Tabela 3.

Tabela 3 - Efeitos principais dos fatores

\begin{tabular}{ccc}
\hline Fator & Efeito & P - valor \\
\hline Solvente & 35,80 & 0 \\
Tempo & 31,58 & 0 \\
Solvente x Método & $-8,640$ & 0,039 \\
\hline
\end{tabular}

$\mathrm{O}$ fator que mais interfere no rendimento é o solvente, favoreceu o processo promovendo um aumento de $35,80 \%$, seguido pelo tempo, que elevou em $31,58 \%$. O solvente e o tempo apresentaram valores significativos ao nível de $5 \%$ de significância $(\mathrm{p} \leq 0,05)$. A interação solvente/método reduziu o rendimento em $8,6 \%$. O erro padrão foi de 3,866.

Os coeficientes de regressão da Tabela 4 permitiram validar um modelo polinomial para as variáveis analisadas que se mostraram significativos na análise de variância.

Tabela 4 - Coeficiente de regressão para as variáveis significativas

\begin{tabular}{cccc}
\hline Fatores & $\begin{array}{c}\text { Coeficiente de } \\
\text { regressão }\end{array}$ & Erro padrão & $\mathrm{P}$ \\
\hline Média/Interação & 67,90141 & 1,933109 & 0 \\
Solvente & 17,89953 & 1,933109 & 0 \\
Tempo & 15,79005 & 1,933109 & 0 \\
Solvente x Tempo & $-1,59140$ & 1,933109 & $-8,398$ \\
\hline
\end{tabular}

O modelo polinomial de terceira ordem da extração por solvente é dado segundo a Equação 1 na qual S é o solvente e T, o tempo. 
Rendimento óleo $(\%)=67,90141+17,89953 S+15,790 T-1,59140 S . T$

A partir do modelo polinomial foi possível obter as curvas de nível para o rendimento apresentadas na Figura 1.

Figura 1 - Curva de nível para rendimento do óleo

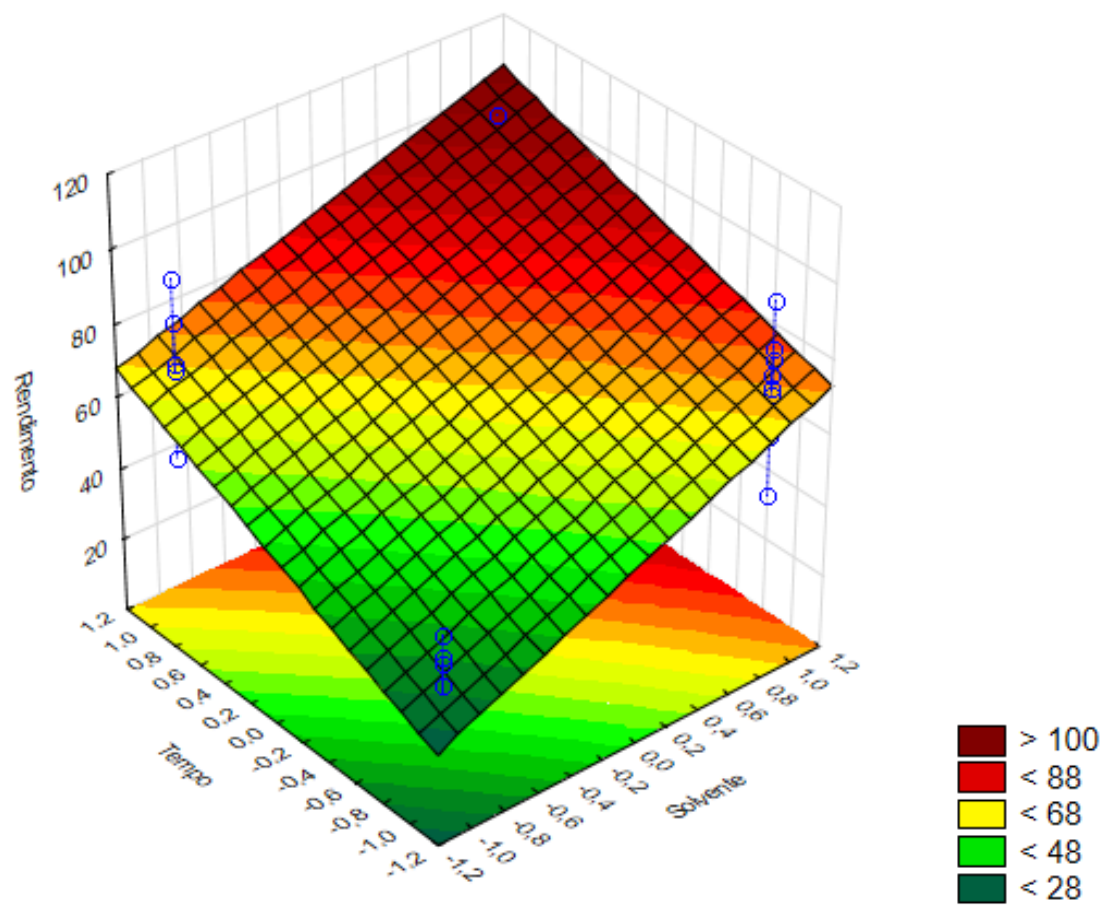

A Figura 1 mostra que o rendimento da extração foi maior quando foi utilizado etanol e tempo 3 horas sendo extraído $100 \%$ de óleo. A melhor condição para a extração por solvente é utilizar etanol num tempo de 3 horas.

\section{CONCLUSÕES}

$\mathrm{Na}$ extração por solvente não houve diferença significativa entre o método aplicado avaliando como uma variável individual, tanto Soxhlet como contínuo podem ser utilizados. Em relação à granulometria, houve um aumento na extração de óleo de $4 \%$ para Tyler \#28 em comparação com \#14/20.

O solvente foi a variável que mais interferiu no processo, aumentando em $36 \%$ o rendimento ao utilizar etanol. $\mathrm{O}$ metanol não se mostrou eficiente em relação ao etanol. $\mathrm{O}$ tempo também foi uma variável bastante interferente, o aumento no tempo de extração conferiu um rendimento $32 \%$ maior.

A análise estatísticas dos dados experimentais permitiu comprovar que a melhor condição operacional do processo de extração é utilizar etanol em um tempo de extração de 3 horas. Essa condição permitiu $100 \%$ de extração do óleo presente na amostra. Além disso, foi possível desenvolver um modelo polinomial do processo de extração por solvente envolvendo as melhores condições. 


\section{AGRADECIMENTOS}

Ao laboratório LASSOP que deu suporte para que a pesquisa fosse realizada e aos professores João Inácio Soletti, Sandra Helena Vieira de Carvalho e Dayana de Gusmão Coêlho pela orientação.

\section{REFERÊNCIAS}

CORREIA, I. M. S.; Extração e Pirólise do Óleo de Girassol (Helianthus annus L.) visando a Produção de Biocombustíveis. Universidade Federal do Rio Grande do Norte, 2009.

GALDÁMEZ, E. V. C. Aplicação Das Técnicas De Planejamento E Análise De Experimentos Na Melhoria Da Qualidade De Um Processo De Fabricação De Produtos Plásticos. Dissertação apresentada à Escola de Engenharia de São Carlos da Universidade de São Paulo, São Carlos, 2002.

MORETTO, E.; FETT, R. Óleos e gorduras vegetais (Processamento e análises). Florianópolis: Editora da UFSC, 1986.

OETTERER, M.; REGITANO-D’ARCE, M. A. B.; SPOTO, M. H.. Fundamentos de Ciência e Tecnologia de Alimentos, São Paulo. Ed. Manole, 2006.

PEREIRA, C. de S. S.; Avaliação De Diferentes Tecnologias Na Extração Do Óleo Do Pinhão-Manso (Jatropha Curcas L). UFRRJ - Dissertação de Pós-Graduação em Engenharia Química. Rio de Janeiro, 2009. 